\title{
Verificação de um modelo teórico entre a empatia, socialização ética e orientação cultural em jovens brasileiros.
}

\author{
Verification of a Theoretical Model Between Empathy, Ethic \\ Socialization and Cultural Orientation in Young Brazilian
}

\author{
Nilton S. Formiga ${ }^{1}$ \\ Faculdade Internacional da Paraíba, Brasil
}

\begin{abstract}
Resumo. O presente estudo tem o objetivo de verificar a associação entre a empatia, a transmissão de valores morais e ética e a orientação cultural em jovens. Teoricamente, sendo a empatia uma disposição funcional das pessoas para as trocas de experiências, afetivas e cognitivas, em relação ao outro, julga-se que este construto é importante para a formação moral e ética do jovem, bem como, para a orientação dos padrões convencionais estabelecidos culturalmente. 427 sujeitos, do sexo masculino e do sexo feminino, de 12 a 19 anos, de instituições privadas e publicas das cidades de João Pessoa-PB e PatrocínioMG responderam a escala multidimensional de reatividade interpessoal de Davis, questões a respeito da crença nos pais e nos professores quanto ao esforço que cada um tive para transmitir/ensinar valores morais e princípios éticos e a escala dos atributos do tipo de orientação cultural individualista e coletivista. Observou-se que a empatia associou-se positivamente, a socialização ética e orientação coletivistas, mas, em relação à orientação individualista, as duas primeiras variáveis se associaram negativamente. Com isso, aqueles que desenvolvem habilidades empáticas na sua relação interpessoal, tanto contribui para uma transmissão dos valores sociais e morais, bem como, uma orientação a cooperação e manutenção das relações interpessoais.
\end{abstract}

Palavras chave. Orientação cultural, empatia, valores e ética, modelo teórico.

Abstract. The present study aims to investigate the association between empathy, transmission of moral and ethical values and cultural orientation in youth. Theoretically, empathy and the functional exchange of experiences layout of people is believed to be important for moral and ethical training of the young, as well as to the orientation of the conventional patterns culturally established. 427 subjects of both genders between the ages of 12- 19 years old of private and public institutions of the city of João Pessoa-PB and Patrocínio-MG answered the multidimensional Davis Interpersonal Reactivity test. This consists on a set of questions about the belief of parents and teachers conveying / teaching moral and ethical principles and scale attributes of individualist and collectivist cultural orientation. It was observed that empathy was positively associated to socialization and ethical collectivist orientation, but in relation to the individualistic orientation, the first two variables were negatively associated. Thus, those who develop empathic abilities in their interpersonal relationships, both contribute to the transmission of social and moral values, as well as to the orientation, cooperation and maintenance of interpersonal relationships.

Keywords. Cultural Orientation, empathy, values and ethics, theoretical model.

\footnotetext{
${ }^{1}$ Nilton S. Formiga. Universidade Federal da Paraíba-Laureate International Universities, Brasil. Endereço para correspondência: Rua Lionildo Francisco de Oliveira, 380. Bairro dos Estados. CEP.: 58030-216. João Pessoa - PB. Brasil. E-mail: nsformiga@yahoo.com.
}

\section{(®) $\Theta \Theta$}




\section{Introdução}

A contemporaneidade tem revelado transformações sociais, econômicas e culturais que vem influenciando a dinâmica indivíduo-sociedade (influências estas que passam pela linguagem, identidade individual e grupal, tecnologia, etc.) e afetando as relações interpessoais no que diz respeito à apreensão de diferentes percepções sobre o saber, o fazer e a experiência que ocorre no entorno psicossocial (Burger, 1985; Kumar, 1997; Bauman, 1998; Lipovetsky \& Charles, 2004; Teixeira, 2005).

Apesar de sugerir que tais mudanças ocorrem para a melhoria da dinâmica homem-ambiente, ainda é possível refletir a respeito da relação social e humana e o processo do significado e do sentido da vida do indivíduo e da sociedade para as pessoas sobre a apreensão e estabelecimento de um modelo de pensamento, sentimento, conduta ética e de habilidades sociais frente aos fatores de proteção do risco e desvio social (Howard, 2000; Jodelet, 1984).

O fato é que essas transformações culturais não surgem no vazio e muito menos ficam nele e que, somente elas (em sua subjetividade) é que são alteradas, quando se considera os contextos e as pessoas do seu entorno. Elas influenciam toda uma dinâmica psicossocial quanto aos modos de pensar e agir, contribuindo para identificar os conflitos existentes entre o cultural e o legal, a conduta grupal e individual, a valoração pelo outro e a valoração por si mesmo, etc.

A questão é que tal condição - a da transformação cultural - geralmente leva os indivíduos e os grupos a adesão às condutas mais individualistas, uma vez que as normas que governam o comportamento social, se não estão sem credibilidade, revelam-se na valorização de um materialismo, utilitarismo e o/ou ideal de imagem social narcísica, deflagrando com isso, um existir fragilizado na relação social do cuidado, da valoração humana na sociedade e direito humano, podendo até convergir em direção de uma conduta desviante para que a própria vontade seja estabelecida (Formiga, 2012a; Formiga \& Souza, 2012).

Desta forma, reflete-se: se o comportamento das pessoas é interdependente com a forma de perceber a situação em que elas se encontram, se assim for, este, surge a partir de uma apercepção capaz de definir a própria realidade em as pessoas estão envolvidas e, consecutivamente, promover uma relação social e interpessoal com seu entorno (Atteslander, 1999; Atteslander, Li, Tanur \& Wang, 1996). Com isso, aqueles indivíduos que priorizam e continuam a ter na sociedade e nas normas sociais que os governam, uma confiança e segurança, provavelmente, manteriam uma postura coletivista, indicando uma crença nos antigos ideais da sociedade, entendida como uma grande família, pronta a cuidar de sujeitos que pertencem a ela; já, o contrário, a priorização de si mesmo e da mudança social e normativa - excessiva - e sem vínculo de direitos e justiça, mas, apenas para atender a seus próprios objetivos, mesmo que prejudique uma dimensão mais ampla (isto é, a sociedade), revela a postura de um sujeito individualista (Lipovetsky \& Charles, 2004; Formiga, 2012b).

Para isso, a orientação cultural apreendida poderia ser influenciada pela disposição das pessoas para as trocas de experiências (cognitiva e afetiva) em relação ao valor e a ação frente a outra pessoa, salientando na internalidade da socialização nas instituições clássicas (por exemplo, a família, tendo os pais como referenciais, e a escola, tendo o professor quanto figura formadora, capazes de transmitir valores e atitudes éticas) a formação dos jovens nos processos socializadores valorativos, éticos e empáticos com o objetivo de fomentar nos jovens a sensibilidade em relação ao outro, gerando assim, condutas na forma que gostariam que fosse feito a eles mesmos.

A empatia: Um construto sobre as reações das pessoas na sua dinâmica interpessoal

A empatia refere-se a uma disposição funcional das pessoas para as trocas de experiências expostas, incondicionalmente, em relação ao outro; concretamente, pode ser definido como uma resposta afetiva de origem evolutiva que é mais apropriada à situação do outro do que da própria pessoa (Wispé, 1990; Decety, Jackson, 2004; Decety, 2005; Enz \& Zoll, 2006; Decety, Michalska \& Akitsuki, 2008). Assim, uma pessoa empática, seria capaz de experimentar 
de forma 'sacrificada' as emoções sentidas por outra pessoa, adotar o ponto de vista do outro, compreender suas motivações e necessidades e atribuir atitudes e comportamentos ao outro com a função de prover ajuda, agregação, cuidado, justiça e solidariedade. (Mehrabian \& Epstein, 1972; Davis 1983; Batson, Tricia, Highberger \& Shaw, 1995; Hoffman, 2000; Batson, Eklund, Chermok, Hoyt \& Ortiz, 2007).

De muitas escalas que buscam mensurar a empatia, a escala desenvolvida por Davis (1983), conhecida no Brasil como Escala Multidimensional de Reatividade Interpessoal (EMRI), é a que, teórica e metodologicamente, possui um corpo teórico bem organizado, bem como, tem sido utilizada como variável explicativa em vários estudos no Brasil que salientam variáveis psicológicas e psicossociais (Camino \& Camino, 1996; Ribeiro, Koller \& Camino, 2002; Rique et al., 2010; Sampaio, Camino \& Roazzi, 2010; Sampaio, Monte, Camino \& Roazzi, 2008). Esta escala é importância porque propõe um instrumento com construtos que condizem com uma visão psicogenética, evolutiva e multidimensional da empatia (Ribeiro, Koller \& Camino, 2002). Segundo Davis (1983), as habilidades empáticas são distribuídas em quatro construtos independentes, os quais avaliam experiências afetivas e cognitivas da pessoa:

No que se refere à experiência cognitiva, destaca-se:

- O construto tomada de perspectiva do outro (refere-se à capacidade cognitiva voltada para a compreensão e coordenação de percepções do outro que visem à solução de conflitos interpessoais e sociais); e fantasia (refere-se a habilidade de se identificar com personagens ficcionais em novelas, filmes e romances e sentir junto com eles, uma adesão involuntária às condições afetivas de alegria, tristeza, raiva etc. e/ou de necessidade destes personagens);

Em relação à experiência afetiva:

- Esta poderá se acessada nas pessoas através da consideração empática (diz respeito à capacidade de avaliar e sentir com o outro, bem como do reconhecer seus afetos e necessidades, que pode ser experimentada no self como uma motivação de cunho pró-social que pode levar ao comportamento de ajuda) e a angustia Pessoal (refere-se a um sentimento de tensão e desconforto, frente à condição de necessidade do outro, podendo gerar comportamentos de afastamento ao invés de comportamentos de ajuda).

Partindo desse pressuposto, o construto da empatia contribui para uma autoavaliação do ser humano sobre o reconhecimento da capacidade de uma ressonância interpessoal, a qual é capaz de gerar uma ética relacional; de acordo com Depraz (2005), essa ética, busca o respeito e compreensão do outro e a inclusão do observador no campo do problema do outro, possibilitando, tanto a quem precisa de ajuda quanto a quem pode ajudar uma disposição para o acolhimento do outro, reabrindo espaço para interação humana, vínculos afetivos e a abertura de canais comunicativos para a relação sócio-humana, estimulando e simulando convicções, desejos, percepções, observação de sentimentos e as emoções do outro, de forma que possas agir em relação ao certo e o errado, não somente para si, mas, para a harmonia do seu espaço social.

\section{A socialização ética: Família e escola querem apenas o bem juvenil}

De forma geral a ética refere-se à preocupação que pessoa, grupo ou instituição tem com o contexto em que o outro está envolvido e com o próprio outro; assim, a maneira de compreender e transmitir as normas socialmente desejáveis tem seu foco na assimilação e apreciação de julgar, distintamente, o bem e o mal, capaz de promover uma ação alicerçada nos costumes, prescrições morais, sentimentos, intenções, etc. (Chauí, 1999; Lalande, 1999).

Sendo esse julgamento ético, de categoria normativa, implica ao sujeito um dever ser; desta maneira, assumindo uma situação imperativa, se estabelece como organizadora da conduta humana, acreditando que ela teria seu início na dinâmica interna da socialização familiar (com os pais ou responsáveis de primeiro grau), mas, podendo estender sua importância em um continuum na escola (com os professores) na busca da harmonia social e psicológica (Jerphagnon, 1992; Markeson, 1993; Vaz, 1993; Chauí, 1999).

Com isso, a assimilação e o agir ético pressupõem 
uma contribuição importante por meio dessas instituições clássicas, com o objetivo de sustentar a vida social e psíquica do homem na modernidade, bem como, inibir supostas inquietudes e angústias causadas pela insistente exigência contemporânea a independência ou individualismo humano excessivo, tangente às normas, regras e os padrões sociais. Esta eticidade, imposta inicialmente, na dinâmica socializadora da família (de forma primária), hipoteticamente, sequencia na escola (na forma secundária) seja pela orientação externa (heterônoma) ou interna (autônoma), a qual, indispensável para a organização de uma maturidade da coesão do corpo social na relação sociedade-indivíduo (Durkheim, 1893/1995; 1894/2004; 1897/2000; Piaget, 2003). É sobre essa dinâmica socializadora da ética que o individuo é inclú́do em um mundo da instituição atitudinal socialmente desejável; isto é, de forma geral, o sujeito passa a conhecer, adquirir e apreender as normas, as regras e a lei que organizam a sua vida social, delegando e dirigindo de maneira funcional, uniforme e organizada, apesar das diferenças existentes entre pessoa-cultura-sociedade, as normas socialmente aceitas.

A partir desse processo socializador da ética, em termos da formação psicossocial do indivíduo, é estabelecido um padrão de comportamento, o qual, compartilhado com o grupo ou instituição de pertença (família, escola, religião, etc.), aponta em direção da aprendizagem e manifestação de costumes, tradições, valores, etc., e que, devendo ser aceito, espera-se que o indivíduo aja sobre esse padrão de conduta para o beneficio do outro e da sociedade (Sherif, 1936; Maxwell, 1999; Licht, 2002). Partindo dessa perspectiva, segundo Eisemberg (1999), mesmo que se possa diferenciar a lei de acordo com o grau de autoconsciência e obrigação que elas envolvem (por exemplo: regularidade da conduta humana e adesão consciente), o individuo não somente deverá ser consciente delas, mas, fazse necessário aderir, a partir dessa consciência, a não violação dos direitos do outro (a não ser que a quebra da norma seja, ainda, para o benefício dos outros). Todo esse processo passa a ser construído a partir da dinâmica socializadora na vida da família, espaço principal para os primeiros estabelecimentos das normas, regras e conduta ética (Formiga, 2011).

Nesse contexto da dinâmica socializadora, o sujeito então, internalizaria normas, padrões, etc. passando a se comportar da forma não somente prevista, mas, que fosse aceito socialmente; analiticamente, a motivação das pessoas a se conformar internamente o seguir uma norma, uma lei, etc., seria gerado nessa dinâmica, fazendo-lhes, inicialmente, sentir a obediência, sob a pena de vivenciar sentimentos de menos valia, como culpa e vergonha, as quais, por sua vez, devem-se ao reforço social obtido na sociedade, a partir de uma relação de custo-benefício (Licht, 2002).

Essa condição torna, coloca o reconhecimento de uma característica que evidencia a organização de um grupo ou sociedade junto a um conjunto de recursos, por meio dos quais, procura-se manter a uniformidade entre seus membros, com objetivo de evitar condutas anômicas (Formiga \& Souza, 2011; Mcdavid \& Harari, 1980). Estas seriam capazes de gerar não apenas uma dinâmica exclusivista para que o sujeito busque, se e somente se, a ele próprio, ser individualista, rompendo com o respeito frente a normas, assumindo-as como responsável para realização dos próprios objetivos, mesmo sabendo que é necessário seguir normas centrado em um padrão cultural.

\section{A perspectiva dos atributos de orientação cultural individualista e coletivista}

Ao se enfatizar a respeito dos padrões convencionais da orientação cultural adotada por cada pessoa, destacase o papel dos atributos dos valores culturais proposto por Triandis (1995). Rokeach (1973) já considerava esse construto como fundamental quando se tratava de explicar os comportamentos das pessoas, o qual seria capaz de orientar tanto as escolhas quanto as atitudes humanas.

De fato, seja na mídia, transeuntes ou especialistas da ciência humana e social, percebe-se que uma preocupação frente à conduta social juvenil diz respeito à cultura individual, estigmatizando-a como a única 'CULTURA' e destacando-a uma condição sine quo non do desenvolvimento sócio-humano dos jovens, 
excluindo a complexidade e diversidade humana frente à gestão e formação da conduta socialmente desejável nas relações interpessoais, fundamentada na assimilação e orientação de atributos culturais coletivistas e individualistas (Formiga, 2004; Formiga, 2012a).

Assim, é pertinente considerar os padrões de orientação cultural de individualismo e coletivismo, uma vez que ao se adotar um ou outro, o indivíduo irá se comportar de forma coerente com este. Por um lado, o individualismo expressa uma tendência ao sucesso, a valorizar a própria intimidade e uma necessidade de adequar-se ao contexto social, visando obter recompensas; por outro, o coletivismo define uma tendência à cooperação e ao cumprimento com relação aos demais; internamente, as pessoas com orientação coletivista, mantêm fortes relações entre si, podendo compartilhar os mesmos interesses (Gouveia, Clemente \& Vidal, 1998).

O individualismo e coletivismo são definidos como sindromes culturais, consistem em compartilhar atitudes, crenças, normas, papeis sociais e definições do eu, sendo os valores dos membros de cada cultura organizados coerentemente sob um tema (Triandis, 1995; 1996). As pessoas que se orientam por um tipo ou outro de orientação cultural, vão se comportar de maneira diferente, seja na forma de se auto-perceber ou nos seus relacionamentos interpessoais. No entanto, deve-se salientar que o individualismo e coletivismo não são necessariamente opostos. Como assinalam Sinha e Tripathi (1994), as pessoas são um pouco de cada um, sendo o contexto ou a situação imediata, que vai definir o estilo mais apropriado de comportamento - o tipo de orientação (Triandis, 1995; Triandis, Chen \& Chan, 1998). Em todo caso, espera-se que, em cada pessoa, predomine uma destas orientações, não se podendo ignorar a possibilidade de coexistência das duas (Schwartz, 1990; Sinhá \& Tripathi, 1994), bem como, sua relação entre esses atributos.

Triandis (1995), ao recuperar a clássica dimensão de poder proposta por Hofstede (1980) que avaliava as dimensões culturais nas empresas, enfatizando o papel do sujeito ou do grupo na dinâmica das sociedades humanas identifica dois atributos chave para diferenciar os principais tipos de individualismo e coletivismo: horizontal e vertical.

O atributo horizontal sugere que as pessoas são similares na maioria dos aspectos, especialmente no status. $O$ conceito vertical põe ênfase em aceitar a desigualdade e privilegiar a hierarquia. Estes atributos se combinam com o individualismo e coletivismo formando quatro tipos de orientação, cada um com uma característica principal que melhor descreve a pessoa que adota cada um destes tipos, a saber:

-Individualismo

Horizontal/ Ser único, diferente dos demais

Vertical/ Orientado ao êxito, ao triunfo

- Coletivismo

Horizontal/Cooperador, que colabora

Vertical/ Cumpridor com os demais, ser servidor

Considerar estes atributos - os de individualismo e do coletivismo - permite relacionar uma variedade de fatos e pensamentos nas múltiplas facetas da vida social e política (Inglehart, 1991). Sabendo-se ainda que quando se deseja explicar comportamentos deve-se recorrer às atitudes, ao reconhecer a natureza atitudinal que estes construtos venham apresentar, é possível que eles contribuam para a explicação de algumas condutas sociais, neste caso, a conduta empática do jovem.

Partindo desses pressupostos, o presente estudo tem como objetivo, a partir da análise e modelagem de equação estrutural no programa AMOS 18.0, verificar a associação entre empatia, socialização ética e o tipo de orientação cultural em jovens. Especificamente, a técnica da análise da Modelagem de Equação Estrutural (MEE) tem a clara vantagem de levar em conta a teoria para definir os itens pertencentes a cada fator, bem como, apresentar indicadores de bondade de ajuste que permitam decidir objetivamente sobre a validade de construto da medida analisada e sua direção associativa entre as inúmeras variáveis.

Desta forma, dois resultados principais podem ser esperados ao trabalhar com essa análise: i) estimativa da magnitude dos efeitos estabelecida entre variáveis, 
as quais estão condicionadas ao fato de o modelo especificado (isto é, o diagrama) estar correto, e ii) testar se o modelo é consistente com os dados observados, a partir dos indicadores estatísticos, podendo dizer que resultado, modelo e dados são plausíveis, embora não se possa afirmar que este é correto (Farias \& Santos, 2000). Atende-se assim, não a certeza total do modelo, mas, a sua probabilidade sistemática na relação entre as variáveis.

Um dos principais objetivos das técnicas multivariadas - neste caso, considera-se a modelagem de equação estrutural - é expandir a habilidade exploratória do pesquisador e a eficiência estatística e teórica no momento em que se quer provar a hipótese levantada no estudo. Apesar das técnicas estatísticas tradicionais compartilharem de limitações, nas quais, é possível examinar somente uma relação entre as variáveis, é de suma importância para o pesquisador o fato de ter relações simultâneas; afinal, em alguns modelos existem variáveis que são independentes em algumas relações e, dependentes em outras. A fim de suprir esta necessidade, a Modelagem de Equação Estrutural examina uma série de relações de dependência simultâneas, esse método é particularmente útil quando uma variável dependente se torna independente em relações subseqüentes de dependência (Silva, 2006; Hair, Anderson, Tatham \& Black, 2005).

De acordo com Farias e Santos (2000), Hair, Anderson, Tatham e Black (2005) e Zamora e Lemus (2008) ao considerar a modelagem estrutural do modelo - isto é, a análise de caminhos (path analysis) - relaciona-se as medidas de cada variável conceitual como confiáveis, acreditando que não existe erro de medida (mensuração) ou de especificação (operacionalização) das variáveis; cada medida é vista como exata manifestação da variável teórica.

Assim considerado, desenha-se o modelo teórico que se pretende tomando a partir elaboração hipotética entre as variáveis independente e dependente, isto é, entre as variáveis latentes e variáveis observáveis, por exemplo: no desenho desse modelo - elaboração da ligação entre as figuras caracterizando as variáveis estudadas um retângulo é considerado como variável observada medida pelo pesquisador; uma elipse é considerada variável latente, isto é, construto hipotético não observado; uma seta com uma ponta indica o caminho ou a relação causal entre duas variáveis; uma seta com duas pontas representa a covariância, isto é, que estas variáveis se associam entre si; por fim, uma bolinha preenchida com um número e letra referem-se a um erro de medida. A partir do momento em que se elabora a hipótese, identifica cada uma dessas figuras associando as variáveis que se quer provar a múltipla influência.

Para que os resultados sejam obtidos faz-se necessário considerar índices de ajuste (escores co-variantes) - os quais destacados na metodologia do presente estudo, na sessão do procedimento - permitindo enfatizar a teoria a que se propõem e sua explicação, simultaneamente, entre as variáveis independentes e dependentes, além de garantir uma melhor avaliação associativa entre as variáveis a que se pretende corroborar no modelo.

A grande importância no uso dos estudos de modelagem de equação estrutural refere-se tanto em relação à segurança dos resultados multivariados, quanto, partindo de um estudo anterior ou de uma perspectiva teórica - ou até, de ambas - avaliando a associação simultânea entre as variáveis testadas (Byrne, 1989; Pilati \& Laros, 2007; Hoe, 2008). Desta forma, espera-se que a empatia esteja associada positivamente, com a socialização ética e a orientação coletivista; por outro lado, a empatia estará associada positivamente, com a socialização ética, sendo ambas as variáveis, associando-se negativamente, a orientação individualista.

\section{Método}

\section{Participantes}

427 sujeitos, do sexo masculino (51\%) e do sexo feminino (49\%), de 12 a 19 anos, do nível fundamental $(38 \%)$ e médio $(62 \%)$ de instituições privadas $(42 \%)$ e publicas (58\%) das cidades de João Pessoa-PB e Patrocínio-MG, compuseram este estudo. A amostra foi não probabilística, pois considerou-se a pessoa que, consultado, se dispôs a colaborar, respondendo o questionário a ele apresentado. 


\section{Instrumentos}

Os sujeitos responderam os seguintes instrumentos:

Escala Multidimensional de Reatividade Interpessoal de Davis - EMRI. Trata-se de um instrumento elaborado por Davis (1983) e adaptado em sua versão original por Sampaio, Guimarães, Camino, Formiga e Menezes (2011) para o contexto brasileiro; em estudo posterior ao desses autores, desenvolvido por Formiga, Sampaio e Guimarães (2011), o qual procurou verificando a acurácia da EMRI, esses autores observaram-se indicadores psicométricos $(\chi 2 / \mathrm{gl}=1.04$, GFI $=0.98$, AGFI $=0.96$, RMR $=0.03$, CFI $=1.00$, RMSEA $(90 \% \mathrm{IC})=0.00(0.00-0.02), \mathrm{CAIC}=1208.51$ e ECVI $=0.76)$ próximos aos encontrado por Sampaio e cols. (2011). Em outro estudo, Formiga (2012b), ainda com amostras brasileiras, corroborou a mesma estrutura psicométrica dessa escala. O instrumento é composto por 26 sentenças que descrevem comportamentos, sentimentos e características relacionadas à empatia, que são utilizadas para avaliar as seguintes dimensões da empatia:

- Angústia pessoal (AP) - avalia as sensações afetivas de desconforto, incômodo e desprazer dirigidas para o self, quando o indivíduo imagina o sofrimento de outrem (por exemplo, Perco o controle quando vejo alguém que esteja precisando de muita ajuda; Fico apreensivo em situações emergenciais, etc.).

- Consideração empática (CE) - esta dimensão relaciona-se aos sentimentos dirigidos ao outro e à motivação para ajudar pessoas em necessidade, perigo ou desvantagem (Ex: Sinto compaixão quando alguém é tratado injustamente; Quando vejo que se aproveitam de alguém, sinto necessidade de protegê-lo, etc.).

- Tomada de perspectiva (TP) - mede a capacidade cognitiva do indivíduo de se colocar no lugar de outras pessoas, reconhecendo e inferindo o que elas pensam e sentem (Ex: Imagino como as pessoas se sentem quando eu as critico; Tento compreender meus amigos imaginando como eles vêem as coisas, etc.).

- Fantasia (FS) - a primeira designa a habilidade de se colocar no lugar de outras pessoas, tomando suas perspectivas e imaginando o que elas pensam ou sentem; a subescala de fantasia avalia a tendência de transpor a si mesmo imaginativamente, colocandose no lugar de personagens de filmes e/ ou livros (Ex: Tenho facilidade de assumir a posição de um personagem do filme; Depois de ver uma peça de teatro ou um filme sinto-me envolvido com seus personagens, etc.).

Cada uma destas subescalas é composta, por uma quantidade específica de itens: FS e CE, sete proposições, AP e TP, seis proposições. Todas elas foram avaliadas por escalas likert, que variam de 1 ("não me descreve bem") a 5 ("descreve-me muito bem"). Escores mais altos indicam níveis mais elevados em cada uma dessas dimensões e a soma dos escores de todas as subescalas é utilizada para calcular o nível global de empatia. O item 2 (Sou neutro quando vejo filmes) deve ter sua pontuação invertida, pois foi elabo $\neg$ rado na direção contrária a dos demais itens da escala. No presente estudo, a escala em questão revelou indicadores muito próximos aos encontrados pelos autores supracitados, tanto para a amostra de Minas Gerais quanto da Paraíba.

Duas questões a respeito da crença nos pais e nos professores quanto ao esforço que, cada um deles, tiveram para transmitir/ensinar valores morais e princípios éticos. Tomando como referência a dinâmica socializadora que eles vivem, o jovem deveria indicar um numero da escala, que representasse o grau de esforço que seus pais e professores, individualmente, empregaram para que eles agissem ética e valorativamente nas suas relações. Assim, eles deveriam responder se os pais e professores: Não se esforçaram, se esforçaram muito, se esforçaram pouco, se esforçaram o máximo possível, fizeram um esforço mediano.

Escala dos atributos do tipo de orientaşão cultural individualista e coletivista. Composto por seis itens que avaliam os atributos que mais caracterizam os sujeitos em relação ao individualismo e coletivismo (por exemplo, Um ser único, diferente dos demais; Orientado ao êxito, ao triunfo; Cooperador, que colabora; Cumpridor com os demais, servidor). 
Formiga e Mota (2009) observaram Alfas de Cronbach aceitáveis pela literatura sobre o tema; realizando uma análise fatorial confirmatória (AFC) e a análise do modelo de equação estrutural (SEM), Formiga (2011) observou que este escala mostrou-se fidedigna quanto a estrutura fatorial já observada pelos autores supracitado, por exemplo: $\chi 2 / \mathrm{gl}=3.01$; GFI = 0.99 e AGFI $=0.97$; TLI $=0.93$; RMSEA $(90 \% \mathrm{IC})=$ $0.05(0.03-0.08)$, CAIC $=131.58$ e ECVI $=0.07$.

O instrumento proposto apresentou garantia de maior confiabilidade fatorial e evidências empíricas para sua aplicação e mensuração no contexto paraibano. Para respondê-lo o jovem deveria ler cada item e indicar o quanto cada um dos atributos lhe caracteriza, para isso, era necessário apontar (com um X ou circulo) numa escala do tipo Likert, com os seguintes extremos: $0=$ Nada Característico e $5=$ Muito Característico, ao lado dos respectivos atributos.

Tanto para amostra total quanto para as amostras de cada Estado, o referente instrumento revelou indicadores psicométricos próximos aos estabelecidos pela literatura estatística, bem como, semelhante aos encontrados pelos autores supracitados.

Caracterização Sócio - Demográfica. Foram elaboradas perguntas que contribuíram para caracterizar os participantes deste estudo (por exemplo, sexo, idade, classe sócio-econômica), bem como, realizar um controle estatístico de algum atributo que possa interferir diretamente nos seus resultados.

\section{Procedimentos}

Todos os procedimentos adotados nesta pesquisa seguiram as orientações previstas na Resolução 196/96 do CNS e na Resolução 016/2000 do Conselho Federal de Psicologia (Conselho Nacional De Saude - CNS, 1996; Associação Nacional de Pesquisa e PósGraduação em Psicologia - ANPEPP, 2000).

\section{Administração}

Colaboradores com experiência prévia na administração da aplicação dos instrumentos foram responsabilizados pela coleta dos dados, e apresentaram-se nas salas de aula como interessados em conhecer as opiniões e os comportamentos dos alunos sobre as situações descritas nos instrumentos.

Solicitou-se a colaboração voluntária dos jovens no sentido de responderem um breve questionário. Após ficarem cientes das condições de participação na pesquisa, assinaram um termo de Consentimento Livre e Esclarecido. Foi-lhes dito que não havia resposta certa ou errada. A todos foi assegurado o anonimato das suas respostas informando que estas seriam tratadas em seu conjunto. As escalas foram então respondidas individualmente.

Apesar de o instrumento ser auto-aplicável, contando com as instruções necessárias para que possam ser respondidos, os colaboradores na aplicação estiveram presentes durante toda a aplicação para retirar eventuais dúvidas ou realizar esclarecimentos que se fizessem indispensáveis. Um tempo médio de 40 minutos foi suficiente para concluir essa atividade.

\section{Análise dos dados}

No que se refere à análise dos dados desta pesquisa, utilizou-se a versão 18.0 do pacote estatístico SPSS para Windows. Foram computadas estatísticas descritivas (tendência central e dispersão). Os seguintes indicadores estatísticos para o Modelo de Equações Estruturais (MEE) foram considerados segundo uma bondade de ajuste subjetiva. Esse programa estatístico tem a função de apresentar, de forma mais robusta, indicadores psicométricos que vise uma melhor construção da adaptação e acurácia da escala desenvolvida, bem como, permita desenhar um modelo teórico pretendido no estudo.

No que se refere à análise dos dados desta pesquisa, utilizou-se a versão 21.0 do pacote estatístico SPSS para Windows. Foram computadas estatísticas descritivas (tendência central e dispersão). Indicadores estatísticos para o Modelo de Equações Estruturais (MEE), efetuados no AMOS GRAFICS na versão 21.0, foram considerados segundo uma bondade de ajuste subjetiva:

- O $\chi^{2}$ (qui-quadrado) testa a probabilidade de o modelo teórico se ajustar aos dados; quanto maior este valor pior o ajustamento. Este tem sido pouco 
empregado na literatura, sendo mais comum considerar sua razão em relação aos graus de liberdade ( $\chi^{2} /$ g.l. $)$. Neste caso, valores até 5 indicam um ajustamento adequado.

- Root Mean Square Residual - RMR - que indica o ajustamento do modelo teórico aos dados, na medida em que a diferença entre os dois se aproxima de zero. Para o modelo ser considerado bem ajustado, o valor deve ser menor que 0.05 .

- O Goodness-of-Fit Index (GFI) e o Adjusted Goodness-of-Fit Index (AGFI) são análogos ao $\mathrm{R}^{2}$ em regressão múltipla. Portanto, indicam a proporção de variância-covariância nos dados explicada pelo modelo. Estes variam de 0 a 1 , com valores na casa $\operatorname{dos} 0,80$ e 0,90 , ou superior, indicando um ajustamento satisfatório (Bilich, Silva \& Ramos, 2006; Hair, Anderson, Tatham \& Black, 2005).

- A Root-Mean-Square Error of Approximation (RMSEA), com seu intervalo de confiança de $90 \%$ (IC90\%), é considerado um indicador de "maldade" de ajuste, isto é, valores altos indicam um modelo não ajustado. Assume-se como ideal que o RMSEA se situe entre 0,05 e 0,08, aceitando-se valores de até 0,10 (Garson, 2003; Kelloway, 1998).

- O Comparative Fit Index (CFI) - compara de forma geral o modelo estimado e o modelo nulo, considerando valores mais próximos de um como indicadores de ajustamento satisfatório (Hair, Tatham, Anderson \& Black, 2005; Joreskög \& Sörbom, 1989).

\section{Resultados}

Neste estudo procurou verificar a associação entre socialização ética, empatia e tipo de orientação cultural em jovens. Para isso, a partir da análise e modelagem de equação estrutural verificou-se o modelo teórico pretendido. Considerou-se um modelo recursivo de equações estruturais efetuando-se o cálculo no programa AMOS 21.0.

Gerou-se um primeiro modelo, o qual avaliou a influência da empatia sobre a socialização ética e orientação cultural coletivista; na figura 1, com as devidas modificações realizadas nos ajustes de erro, encontrou-se o modelo esperado, este, apresentou a seguinte razão: $\chi^{2} / \mathrm{gl}=1.42, \mathrm{RMR}=0.04$, GFI $=0.99$, $\mathrm{AGFI}=0.97, \mathrm{CFI}=0.99, \mathrm{RMSEA}=0.03(0.00-0.06)$. Observou-se que o peso da variável da empatia $(\lambda=$ $0.57)$ associou-se, positivamente, a socialização ética e ao tipo de orientação coletivista $(\lambda=0.25)$, tendo estas duas últimas variáveis, também, apresentado um escore associativo positivo $(\lambda=0.81)$ (ver figura 1$)$.

Após a comprovação desse modelo para amostra total, questionou-se se o mesmo estaria associado em suas variáveis para as amostras separadas (isto é, para a amostra de Patrocínio-MG e João Pessoa-PB); assim, efetuou-se o mesmo cálculo, considerando também, semelhante caminho associativo atribuído ao modelo já verificado. Observaram resultados que corroboram o mesmo modelo, os quais revelaram indicadores psicométricos muito próximos aos já observados: na amostra dos jovens de Patrocínio-MG houve a seguinte razão estatística, $\chi^{2} / \mathrm{gl}=2.34, \mathrm{RMR}=0.05, \mathrm{GFI}=0.98$, AGFI $=0.96$, CFI $=0.98$, RMSEA $=0.04(0.01-0.05)$, esta, comprovou a associação positiva da empatia $(\lambda=$ $0.43)$ com a socialização ética e ao tipo de orientação coletivista $(\lambda=0.18)$ e com estas duas últimas variáveis se associando positivamente $(\lambda=0.73)$; na amostra dos jovens de João Pessoa-PB, os resultados também, estiveram próximos ao esperado, $\chi^{2} / \mathrm{gl}=1.87, \mathrm{RMR}=$ 0.03, GFI $=0.99$, AGFI $=0.97$, CFI $=0.99$, RMSEA $=0.03(0.00-0.04)$, o qual comprovou que a empatia se associou positivamente, com a socialização ética $(\lambda=$ $0.38)$ e ao tipo de orientação coletivista $(\lambda=0.23)$, com estas últimas se associando, também, de forma positiva entre si $(\lambda=0.67)$.

Em um segundo modelo, procurou-se verificar a influência entre a empatia, socialização ética e orientação cultural individualista; para isso, também, foi considerado semelhante caminho hipotético atribuídos as variáveis do modelo anterior, mas, tendo sua base explicativa em direção da orientação individualista. $\mathrm{Na}$ figura 2, feitas as necessárias modificações nos ajustes de erro, encontrou-se que o modelo hipotetizado apresentou a seguinte razão: $\chi^{2} / \mathrm{gl}=1.50, \mathrm{RMR}=$ 0.04, GFI $=0.98$, AGFI $=0.96$, CFI $=0.99$, RMSEA $=0.03(0.00-0.07)$; estes indicadores revelaram que o 
peso lambda $(\lambda)$ da variável da empatia associou-se, positivamente, com a socialização ética $(\lambda=0.54)$, porém, ambas, associaram-se, negativamente, ao tipo de orientação individualista (respectivamente, $\lambda=$ -0.12 e $\lambda=-0.25)$, (ver figura 2 ).

Também corroborada essa hipótese, optou-se em seguir direção semelhante realizada no primeiro modelo para as diferentes amostras; com isso, observaram-se os seguintes resultados: em relação a amostra dos jovens de Patrocínio-MG, tendo os indicadores psicométricos revelado resultados aceitáveis $\left[\chi^{2} / \mathrm{gl}=2.17, \mathrm{RMR}=\right.$ 0.04, GFI $=0.97$, AGFI $=0.95$, CFI $=0.98$, RMSEA $=0.05(0.02-0.08)]$ comprovando a associação positiva da empatia $(\lambda=0.46)$ com a socialização ética, tendo estas duas variáveis se associando negativamente com a orientação cultural individualista (respectivamente, $\lambda=0.16$ e $\lambda=0.31$ ); na amostra dos jovens de João Pessoa-PB, os resultados também, estiveram próximos ao esperado, $\chi^{2} / \mathrm{gl}=1.75, \mathrm{RMR}=0.03, \mathrm{GFI}=0.98$,

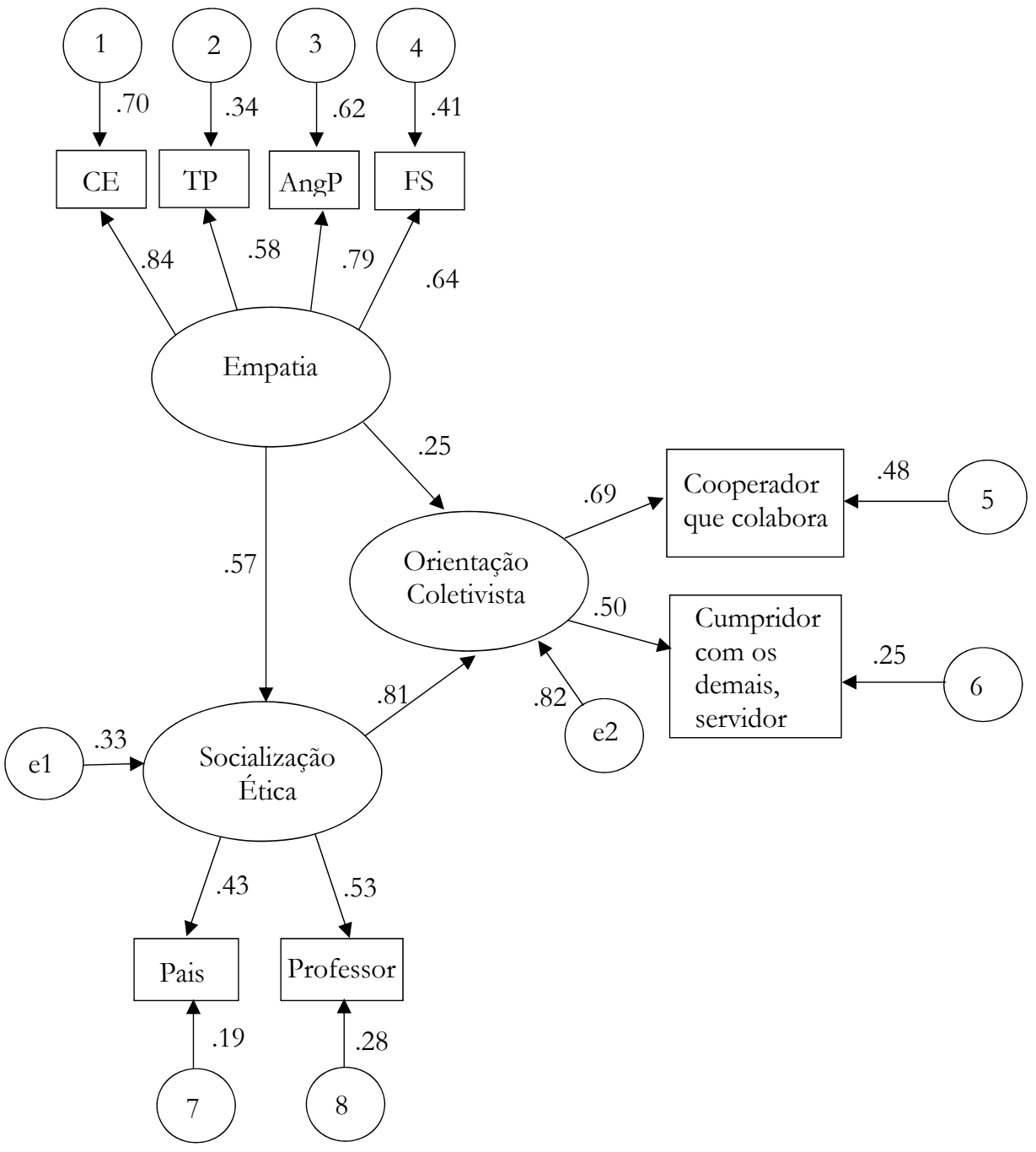

Figura 1. Modelagem estrutural da empatia sobre a socialização ética e o tipo de orientação cultural coletivista em jovens. 


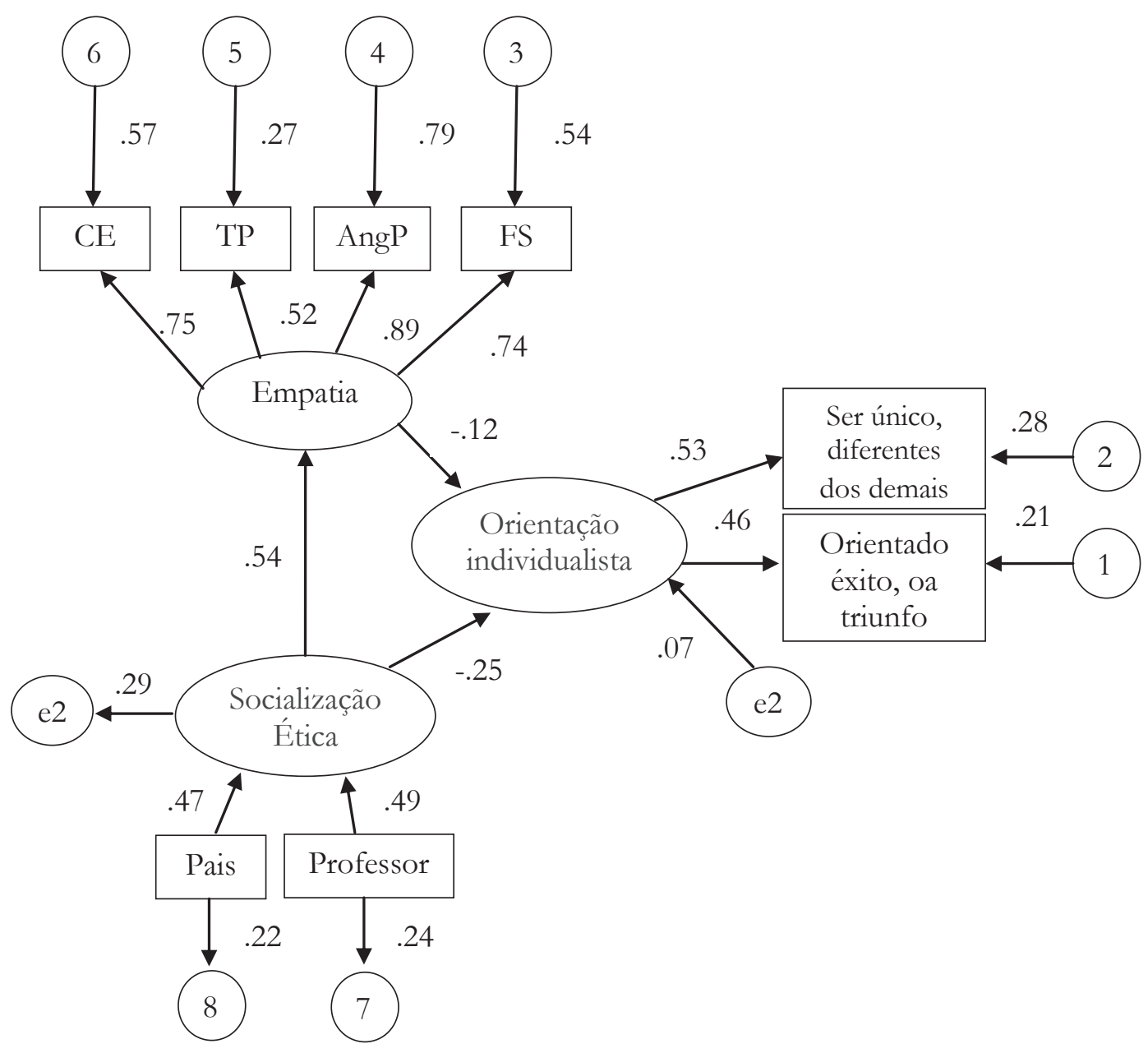

Figura 2. Modelagem estrutural da empatia sobre a socialização ética e o tipo de orientação cultural individualista em jovens.

AGFI $=0.97$, CFI $=0.99$, RMSEA $=0.03(0.00$ 0.05) corroborando a associação positiva da empatia com a socialização ética $(\lambda=0.43)$, com essas ultimas variáveis se associando negativamente a orientação individualista (respectivamente, $\lambda=0.14$ e $\lambda=0.27$ ).

A partir desses resultados, considera-se que os modelos propostos foram comprovados e que apresentaram indicadores psicométricos quanto à modelagem teórico-empírica aceito na literatura estatística (Joreskög \& Sörbom, 1989; Hair, Anderson, Tatham \& Black, 2005). Sendo assim, não somente corroboram-se as hipóteses estabelecidas, mas também, o poder predito da perspectiva teórica da empatia sobre a socialização ética e a orientação cultural.

O fato é que os sujeitos ao desenvolverem habilidades empáticas no seu entorno sócio-humano, não apenas contribui para que os acreditem na socialização ética 
vivida pelos mesmos, mas também, que tais condições (a habilidade empática e a transmissão dos valores sociais e morais), provavelmente, orientariam o sujeito ao coletivismo (isto é, orientação a cooperação e cumprimento com relação aos demais, manutenção das relações interpessoais e o compartilhar dos mesmos interesses), por outro lado, da empática e transmissão da conduta ética, seria inibidora do individualismo.

Tal reflexão poderá ser avaliada ao se observar os lambdas associativos entre as variáveis destacadas (ver Figura 1 e 2), estas não apenas apresentaram uma lógica de direção e força estatística correspondente a teoria enfatizada, mas, também, indicadores psicométricos para o modelo teórico (por exemplo, $\chi 2 / g 1, R M R$, GFI, AGFI, CIF e RMSEA) que garante a consistência associativa entre as variáveis.

\section{Discussão}

Esse modelo, com base na perspectiva teórica da empatia desenvolvida por Davis (1983), autor esse, que defende uma base psicogenética e evolutiva no desenvolvimento das habilidades empáticas (consideração empática, tomada de perspectiva, angustia pessoal e fantasia), aponta em direção da importância de se socializar os jovens nessas habilidades, seja, na escola, na família ou em ambas as instituições, pois contribuiria para uma socialização formadora da ética e valores morais, mas, também, da aderência a uma melhor orientação (cultural), especialmente, a orientação coletivista, a qual decorre do seu desenvolvimento psicossocial, principalmente, quando se pretende, frente a exigência contemporânea de condutas individualistas e narcísicas, encaminhar os jovens na formação de um comportamento prósocial e cumpridores das normas sociais, previamente, estabelecida para a relação com os outros e a sociedade; estas, seriam capazes de manter tanto a consistência de um vinculo social quanto na estrutura e funcionalização de uma organização que gere, na interpessoalidade, interesses que preservem a harmonia social e humana.

Acredita-se que a orientação - seja de individualismo ou coletivismo - por não ocorrer no vazio social, poderia ser influenciada por variáveis que mensurassem o tema da ética ou moral. Tendo refletido nessa direção observou-se que essa associação é viável, salientando que, na perspectiva de Davis (1983), o sujeito ao assimilar as habilidades empáticas, ele não apenas seria socializado nestas habilidades com um todo, mas, desenvolveria, dependendo do foco socializador, habilidades empáticas específicas (por exemplo, a consideração empática, tomada de perspectiva, angústia pessoal e fantasia), pois, este construto, passa pela avaliação que o sujeito faz das experiências afetivas e cognitivas conduzindo ao sujeito desenvolver o respeito, a compreensão do outro e participação no espaço sócio-cognitivo do observador no campo dos problemas do outro, podendo promover agregação, cuidado, solidariedade, etc. (Wispé, 1990; Sampaio, Monte, Camino \& Roazzi, 2008; Sampaio, Guimarães, Camino, Formiga \& Menezes, 2011).

Neste sentido, para que tal condição ocorra, o sujeito precisaria estar disposto às aberturas do espaço interpessoal e afetivo estimulando e/ou simulando convicções, desejos, percepções, sentimentos, etc., que permita a ele se colocar no lugar do sentimento e emoção do outro, porém, não sendo o outro (Formiga, 2012b); isto somente seria possível, com base nesses resultados, se e somente se, o desenvolvimento e assimilação da empatia contribuíssem para a orientação cultural de coletivismo, já que este construto valoriza a harmonia social e preservação do grupo e tradições.

Obviamente, o desenvolvimento da empatia não impediria as orientações individualistas, já que ambas as orientações - coletivismo e individualismo - segundo Sinha e Tripathi (1994), não devem ser consideradas opostas entre si, pois às pessoas poderão apreender uma ou outra forma dessas orientações a partir do contexto ou situação em que estiverem inseridas, as quais, para esses autores, definirá o estilo mais apropriado de conduta. O desenvolvimento da empatia seria, então, uma condição crucial para que a pessoa priorizasse melhor o tipo de orientação especialmente, a coletivista - que assumiria nas relações quando no momento de se auto-perceber e perceber os relacionamentos interpessoais podendo com isso agir ética e moralmente. 
A proposta desse modelo centrou-se na perspectiva da teoria da empatia, desenvolvida por Davis (1983) e esta influenciaria a orientação cultural, contribuindo para que as pessoas se guiem por meio da perspectiva cultural com vista a uma sociedade mais integrada e preocupada com o outro e o seu entorno social, ao invés da valorização de condutas mais egoístas e que preze somente a si mesmo. Ao gerar esse modelo, busca-se discutir a concepção de Formiga e Souza (2012), quando se pretende elaborar uma intervenção para a mudança de comportamento a partir da orientação cultural que os jovens atualmente se guiam; deve-se intervir nas dimensões da empatia, pois, a partir desse construto organizado no espaço cognitivo do sujeito, provavelmente, este a se orientar mais de forma coletivista do que individualista.

Diante de uma sociedade que tem investido em um 'excessivo consumo' nas suas relações interpessoais, conduzindo as pessoas a objetos ou coisas, desvalorizando as relações consistentes e duradouras, ao realizar um estudo com o foco na empatia busca ir além de um simples resgate sobre a importância da humanidade, aponta-se em direção de uma necessidade de construir conhecimentos e formar suportes afiliativos que seja capaz de gerar um sistema de valoração do ser humano que alcance um grau de auto-conhecimento de e para si, bem como, dos outros e para eles desenvolvendo-se social e psiquicamente em busca do direito humano e de ser humano (Berlin, 1997).

\section{Considerações finais}

Espera-se que os objetivos deste estudo tenham sido cumpridos, principalmente, no que diz respeito verificação do modelo causal entre a empatia, socialização ética e o tipo de orientação cultural em jovens; este poderá ser empregado em áreas de estudo que cooperam com a psicologia, por exemplo, educação, sociologia, serviço social, etc. Mas, apesar dos resultados serem satisfatórios, faz-se necessário, para maior qualidade do estudo com essas variáveis, ter em conta aspectos mais específicos ou universais de cada contexto, quando se pretender avaliar tais variáveis em outras culturas (Muenjohn \& Armstrong,
2007; Triandis et al., 1993; Triandis, 1995; Van De Vijver \& Leung, 1997). Com isso, aponta-se para a seguinte direção em estudos futuros:

i) conhecer os aspectos que podem ser comuns a todas as culturas e aqueles que são específicos, contribuindo para consolidar um marco teórico da empatia, socialização ética e o tipo de orientação cultural, já que, considerando os resultados encontrados é possível que estas variáveis venham se diferenciar entre si devido aos contextos sociais, econômicos e políticos. ii) o que fazer no futuro em relação aos estudos com essas escalas? Pretende-se reunir evidências adicionais da consistência intra, inter e pan-culturais em relação a estas medidas em um modelo teórico, bem como, a realização estudos que avaliasse além das experiências empáticas, as dimensões da empatia de forma especifica (por exemplo, a tomada de perspectiva do outro, fantasia, consideração empática e angustia pessoal), já que para Davis (1983) tais dimensões podem ser avaliadas em um conjunto geral tida como reatividade interpessoal, mas, também, através de cada uma dessas dimensões; outro estudo de grande utilidade seria avalia as mesmas variáveis em diferentes contextos educacionais, sóciodemográficos e religiosos; seria também importante relacionar ao conjunto dessas variáveis, a realização de uma análise de variância, controlando o gênero, a idade e a classe social; por fim, outro estudo importante seria o de avaliar a convergência dessas variáveis na dinâmica familiar e escolar, colocando pais, professores e jovens para responder o mesmo instrumento a fim de comparar o processo socializado e sua transmissão para a formação da empatia, ética e valores e orientação cultural em jovens.

\section{Referências}

Associação Nacional de Pesquisa e Pós-Graduação em Psicologia - ANPEPP. (2000). Contribuicões para a discussão das Resoluções CNS no. 196/96 e CFP No 016/2000. Recuperado da: http://www.anpepp.org. br/XIISimposio/Rel_ComissaoEticasobre_Res_ CNS_e_CFP.pdf2000

Atteslander, P., Li, H., Tanur, J., \&, Wang, Q. (1996). A potential social warning instrument. Relatório final do 
projeto sobre anomia na China. Swiss Institute for Development. Biel: Switzerland.

Atteslander, P. (1999). Social Change, Development and Anomie. In Peter Atteslander, Bettina Gransow \& John Western (Org). Comparative anomie research: hidden barriers - bidden potential for social development. Sidney: Ashgate.

Batson, C. D., Eklund, J. H., Chermok, V. L., Hoyt, J. L., \& Ortiz, B. G. (2007). An additional antecedent of empathic concern: valuing the welfare of the person in need. Journal of Personality and Social Psychology, 93 (1), 65-74.

Batson, D. C., Tricia, R. K., Highberger, L., \& Shaw, L. L. (1995). Immorality From Empathy-Induced Altruism: When Compassion and Justice Conflict. Journal of Personality and Social Psychology, 68 (6), 1042-1054.

Bauman, Z. (1998). O Mal-Estar da Pós-Modernidade. Rio de Janeiro: Jorge Zahar Ed.

Berlin, I. (1997/2002). Estudos sobre a bumanidade. Uma antologia de ensaios. São Paulo: Companhia das letras.

Bilich, F., Silva, R., \& Ramos, P. (2006). Análise de flexibilidade em economia da informação: modelagem de equações estruturais. Revista de Gestão da Tecnologia e Sistemas de Informação, 3(2), 93-122.

Bürger, P. (1988). O declínio da era moderna. Revista Novos Estudos CEBRAP, 20, 81-95.

Byrne, B. M. (1989). A primer of LISREL: Basic applications and programming for confirmatory factor analytic models. New York: Springer-Verlag.

Camino, C., \& Camino, L. (1996). Julgamento moral, emoção e empatia. In Z. D. Trindade \& C. Camino (Eds.), Cognição social e juiro moral (Coletâneas da ANPEPP). (109-135). Rio de Janeiro: Associação Nacional de Pesquisa e Pós-graduação em Psicologia.

Chauí, M. (1999). Convite à Filosofia. São Paulo-SP: Atica.

Conselho Nacional De Saúde - CNS. (1996). Diretrizes e Normas Regulamentadoras de Pesquisas Envolvendo Seres Humanos. Recuperado em 02 de Setembro de 2011, da WEB (página da WEB): http://conselho.saude. gov.br/resolucoes/reso_96.htm
Davis, M. H. (1983). Measuring individual differences in empathy: Evidence for a multidimensional approach. Journal of Personality and Social Psychology, 44, 113-126.

Decety J., Michalska K. J., \&, Akitsuki, Y. (2008). Who caused the pain? A functional MRI investigation of empathy and intentionality in children. Neuropsychologia. 46, 2607-2614.

Decety, J. (2005). Perspective taking as the royal avenue to empathy. In B. F. Malle e S. D. Hodges (Eds.), Other minds: How bumans bridge the divide between self and other. (143-157). New York: Guilford Publications.

Decety, J., \&, Jackson, P. L. (2004). The functional architecture of human empathy. Behavioral and Cognitive Neuroscience Reviews. v. 3, pp.71-100.

Depraz, N. (2005). A ética relacional: uma prática de ressonância interpessoal. Revista do departamento de Psicologia da UFF, 17 (2), 19-34.

Durkheim, É. (1995). As regras do método sociológico. São Paulo, Ed. Martins Fontes. Publicado originalmente em 1893.

Durkheim, É. (2004). Da Divisão Social do Trabalho. São Paulo, Ed. Martins Fontes. Publicado originalmente em 1930.

Durkheim, É. (2000). O suicídio. São Paulo, Ed. Martins Fontes. Publicado originalmente em 1897.

Eisemberg, M. (1999). Corporate law, social norms and belief systems. Berkeley Olin Program in Law \& Economics, Working Paper Series, 30, 1-63.

Enz, N., \& Zoll, N. (2006). Cultural differences in empathy between China, Germany and the UK. Recuperado em 23 de novembro de 2006, de www.nicve.salford.ac.uk/ elvis/ resources/empathy.

Farias, S. A., \& Santos, R. C. (2000). Modelagem de Equações Estruturais e Satisfação do Consumidor: Uma investigação teórica e prática. Revista de Administração Contemporânea, 4 (3), 107-132.

Formiga, N. S. (2012a). Teste empírico de um modelo teórico entre o estilo de orientação cultural e 
as condutas desviantes em jovens de diferentes contextos sócio-escolares. Psicologia Argumento, 30 (69), 369-377.

Formiga, N. S. (2012b). Um estudo intracultural da consistência estrutural da escala multidimensional de reatividade interpessoal (EMRI). Revista Salud \& Sociedad, 3 (3), 251-262.

Formiga, N. S. (2011). Valoração da família e condutas desviantes: testagem de um modelo teórico. Psico, 42, 376-385.

Formiga, N. S. (2004). O tipo de orientação cultural e sua influência sobre os indicadores do rendimento escolar. Psicologia. Teoria e Prática, 16 (1), 13-29.

Formiga, N. S., \&, Mota, H. M. (2009). Estilo da orientação cultural e condutas desviantes: Um estudo correlacional em jovens paraibanos. Cadernos de Pesquisa Interdisciplinar em Ciências Humanas, 10 (97), 158-180

Formiga, N. S., Sampaio, L. R., \& Guimaraes, P. R. B. (2015). How many dimensions measure empathy? Empirical evidence multidimensional scale of interpersonal reactivity in brazilian. Eureka, 12 (1), $94-105$.

Formiga, N. S., \& Souza, M.A. (2012). Tipo de orientação cultural e empatia em brasileiros: Verificação de um modelo teórico. Estudos Interdisciplinares em Psicologia, 3 (2), 139-161.

Formiga, N. S., \& Souza, M. A. (2011). Escala de sentimento anômico: Verificação de sua estrutural fatorial em brasileiros. Revista de psicologia da Gepu, 2 (2), 80-97.

Garson, G. D. (2003). PA 765 Statnotes: An online textbook. Endereço de página Web: http://www2. chass.ncsu.edu/garson/pa765/statnote.htm

Gouveia, V.V., Clemente, M. \& Vidal, M. A. (1998). España desde dentro: el individualism y el colectivismo como rasgos diferenciadores de las Comunidades Autónomas. Sociedad y Utopia. Revista de Ciencias Sociales, 11, 167-179.

Hair,J. F., Tatham, R. L., Anderson, R. E., Black, W. (2005). Análise Multivariada de Dados. Porto Alegre: Bookman.
Hoe, L. S. (2008). Issues and procedures in adopting structural equation modeling technique. Journal of applied quantitative methods, 3 (1), 76-83.

Hoffman, M. L. (2000). Empathy and moral development: Implications for caring and justice. New York: Cambridge University Press.

Hofstede, G. H. (1980). Culture's consequences: International differences in work-related values. Newbury Park: Sage.

Howard, G. S. (2000). Adapting human lifestyles for the 21 st century. American Psychologist, 55 (5), 509-515.

Inglehart, R. (1991). El cambio cultural en las sociedades industriales avanzadas. Madrid: Centro de Investigaciones Sociológicas / Siglo XXI Editores.

Jerphagnon, L. (1992). História das grandes filosofias. São Paulo-SP: Martins Fontes.

Jodelet, D. (1984). Représentation sociale: phénomènes, concept et théorie. In: S. Moscovici (Ed.) Psychologie Sociale. (pp. 357-378). Paris: Presses Universitaires de France.

Joreskög, K., \&, Sörbom, D. (1989). LISREL 7 user's reference guide. Mooresville: Scientific Software.

Kelloway, E. K. (1998). Using LISREL for structural equation modeling: A researcher's guide. Thousand Oaks, CA: Sage Publications.

Kumar, K. (1997). Da sociedade pós-industrial à pósmoderna: novas teorias sobre o mundo contemporâneo. Rio de Janeiro: Zahar.

Lalande, A. (1999). Vocabulário Técnico e crítico da filosofia. São Paulo-SP: Martins Fontes.

Licht, A. (2002). The pyramid of social norms. Journal of Economic Behavior and Organization, 11, 1-25.

Lipovetsky, G., \&, Charles, S. (2004). Os Tempos Hipermodernos. São Paulo: Barcarolla.

Markenson, R. (1993). Ética e modernidade. Revista de filosofia, 2, 3-7.

Maxwell, S. (1999). The social norms of discrete consumer exchange: classification and quantification. American Journal of Economics and Sociology, 58 (4), 999-1018. 
McDavid, J. W., \& Harari, H. (1984). Psicologia e comportamento social. Rio de Janeiro: Interciência.

Mehrabian, A., \&, Epstein, N. (1972). A measure of emotional empathy. Journal of Personality, 40, 525-543.

Muenjohn, N., \& Armstrong, A. (2007). Transformational Leadership: The Influence of Culture on the Leadership Behaviours of Expatriate Managers. International Journal of Business and Information, 2 (2), 265-283.

Piaget, J. (2003). Seis estudos de psicologia. Rio de Janeiro: Forense Universitária. ( $24^{a}$ ed., obra original publicada em 1964).

Pilati, R., \&, Laros, J. A. (2007). Modelos de equações estruturais em Psicologia: conceitos e aplicações. Psicologia: Teoria e Pesquisa, 23 (2), 205-216.

Ribeiro, J., Koller, S. H., \& Camino, C. (2002). Adaptação e validação de duas escalas de empatia para uso no Brasil. Estudos de psicologia, 18 (3), 43-53.

Rique, J., Camino, C., Formiga, N. S., Medeiros, F. \& Luna, V. (2010). Empatia e Perdão Interpessoal. Interamerican Journal of Psychology, 44 (3), 515-522.

Rokeach, M. (1973). The Nature of Human Values. New Yark: Free Press.

Sampaio, L. R., Camino, C. P. S. \& Roazzi, A. (2009). Revisão de aspectos conceituais, teóricos e metodológicos da empatia. Psicologia: ciência e profissão, 29 (2), 212-227.

Sampaio, L. R., Guimarães, P. R. B., Camino, C. P. S., Formiga, N. S. \& Menezes, I. G. (2011). Estudos sobre a dimensionalidade da empatia: tradução e adaptação do Interpersonal Reactivity Index (IRI). Psico, 42 (1), 67-76.

Sampaio, L. R., Monte, F. C., Camino, C. \& Roazzi, A. (2008). Justiça distributiva e empatia em adolescentes do nordeste brasileiro. Psicologia: Reflexão e Crítica, 21(2), 275-282.
Sherif, M. (1936). The psychology of social norms. New York: Harper \& Brothers.

Silva, J. S. F. (2006). Modelagem de Equações Estruturais: Apresentação de umametodologia. Dissertação (Mestrado em Engenharia de Produção). Universidade Federal do Rio Grande do Sul. Recuperado da: http://hdl. handle.net/10183/8628.

Schwartz, S. H. (1990). Individualism-collectivism: Critique and proposed refinements. Journal of Cross-Cultural Psychology, 21, 139-157.

Teixeira, E. B. (2005). Aventura pós-moderna e sua sombra. São Paulo-SP: Paulus.

Triandis, H.C. (1995). Individualism and collectivism. Boulder, CO: Westview Press.

Triandis, H. C., Chen, X. P., \& Chan, D. K. (1998). Scenarios for the measurement of collectivism and individualism. Journal of Cross-Cultural Psychology, 29 (2), 275-289

Triandis, H. C., Mccusker, C., Betancourt, H., Iwao, S., Leung, K., Salazar, J. M., Setiadi, B., Sinha, B. P., Touzard, H., \&, Zaleski, Z. (1993). Na etic-emic analysis of individualism and collectivism. Journal of cross-cultural psychology, 24 (3), 366-383.

Van De Vijver, F., \&, Leung, K. (1997). Methods and data analysis for cross-cultural research. Thousand Oaks, CA: Sage Publications.

Vaz, H. C. L. (1993). Escritos de filosofia II: Ética e cultura. São Paulo-SP: Loyola.

Wispé, L. (1990). History of the concept of empathy. In: N. Eisenberg \& J. Strayer (org), Empathy and its development. (pp 17-37). New York: Cambridge University Press.

Zamora, C. S., \& Lemus, I. S. (2008). Modelos de Ecuaciones Estructurales: ¿Qué es eso? Ciencia \& Trabajo, 10 (29), 106-110.

Recibido: 19 de fevereiro de 2015 Aceptado: 5 de março de 2016 